\title{
HIGH-VOLTAGE GAIN DC-DC CONVERTER FOR PHOTOVOLTAIC APPLICATIONS IN DC NANOGRIDS
}

\author{
Yury Pontes ${ }^{1}$, Carlos Elmano de A. e Silva ${ }^{2}$, Edilson Mineiro Sá Jr. ${ }^{3}$ \\ ${ }^{1}$ Federal University of Ceará (UFC), Sobral -CE, Brazil \\ ${ }^{2}$ Federal University of Ceará (UFC, Sobral -CE, Brazil \\ ${ }^{3}$ Federal Institute of Education, Science and Technology (IFCE), Sobral-CE, Brazil \\ e-mail: yuryeletrica@hotmail.com, carloselmano@gmail.com edilson.mineiro@gmail.com
}

\begin{abstract}
Photovoltaic (PV) systems used in DC Nanogrids present prominent advantages associated with low maintenance need and operation costs. Owing to the low output voltage of the PV module, highly efficient highvoltage gain DC-DC converters are required for connection with the DC nanogrid. This work presents a novel DC-DC converter topology with current source characteristic for $\mathrm{PV}$ applications and current injection in DC nanogrids. The introduced converter uses coupled inductors and switched capacitors to achieve high voltage gain with low component count and without using extreme duty ratios. Besides, the main switch is turned on with nearly zero current, thus contributing to minimized switching losses. The qualitative and quantitative analyzes of the circuit are presented in detail and a prototype rated at $200 \mathrm{~W}$ is developed and evaluated in the laboratory. Experimental results demonstrate efficient renewable energy conversion, where the maximum efficiency is $96.8 \%$.
\end{abstract}

Keywords - DC Nanogrids, Grid connected, High Stepup DC-DC converter, High voltage gain, Photovoltaic (PV).

\section{INTRODUCTION}

The continuous evolution of semiconductor technology has allowed the improved use of DC distribution systems [1]-[7], with consequent increase of efficiency due to the lack of acDC converters typically required to provide power factor correction [5].

By definition, a DC nanogrid is a DC distribution system where one or more DC energy sources, e.g., photovoltaic modules, fuel cells, DC generators, among others, provide power to a DC bus in low power plants [8], [9].

A DC nanogrid can operate in standalone mode or connected to a local power grid. It is also possible to distribute energy through an ac bus, i.e., ac nanogrid, or using a hybrid approach [10]-[14].

Since most renewable energy sources operate with DC quantities, as well as energy storage devices (ESDs) and often electronic loads, DC nanogrids become more efficient, due to less energy conversion stages [5], with prominent advantages over their ac counterparts [15]-[18].

\footnotetext{
Manuscript received 04/06/2020; first revision 07/16/2020; accepted for publication 11/09/2020, by recommendation of Editor Demercil de Souza Oliveira Jr http://dx.doi.org/10.18618/REP.2020.4.0021
}

The use of photovoltaic (PV) systems in DC nanogrids is quite attractive due to the low maintenance and operating [9]. In this context, DC buses rated at $380 \mathrm{~V}$ are widely employed in several applications [19]-[21]. Since the PV modules typically provide low voltages rated between $20 \mathrm{~V}$ and $50 \mathrm{~V}$, the series connection of PV modules is employed to obtain higher voltages, which allows the use of basic DC-DC converters in the interconnection between PV modules and the DC bus [22]. In such conditions, partial or total shading can compromise the operation at the maximum power point (MPP) [23]. Therefore, the use of high-voltage gain DC-DC converters is an alternative, since it allows the individual tracking of the MPP in each module, thus optimizing the extraction of power and bringing system modularity.

Several high-voltage gain DC-DC converter topologies have been proposed so far in the literature [8], [9], [24]-[32] Among the existing approaches the extend conversion range, cascaded converters, voltage multipliers, multilevel converters, interleaved converters, switched capacitors and coupled inductors can be highlighted [33]-[35]. The use of coupled inductors has drawn significant attention, since it allows obtaining a high static gain while using few components in the power circuit. However, if the turns ratio is high, the voltage across the output diode will also be. In addition, resonance between the leakage inductance and the intrinsic capacitance of the output diode may cause overvoltage on the active switch, thus leading to the need of clamping circuits [36], [37].

A circuit composed of a diode and a capacitor was employed in [36] to provide the active clamping of the voltage across the Metal Oxide Semiconductor Field Effect Transistor (MOSFET), as the energy associated with the leakage inductance can be absorbed. A family of high-voltage gain converters based on coupled inductors and distinct configurations for the clamping capacitor was introduced in [37]. Besides, the leakage inductance is used to control the falling rate of the current through the output diode, thus minimizing reverse recovery issues. The use of clamping capacitors associated with distinct positions in a coupledinductor-based boost converter was also analyzed in [38], as the voltage stresses on the capacitors are minimized without changing the operating principle of the converter.

Most high-voltage gain converters described in the literature have an output with voltage source characteristic. 
Therefore, an eventual voltage disturbance in the DC bus can cause current peaks in the output of the converter and reduce the life of the capacitors [39]. In addition, devices connected to the same bus operating at different frequencies may cause beat frequency oscillations [39]. In this context, DC-DC converters with current source characteristic at the output has the output current limited by output inductor, allowing the converter to be connected to a voltage bus without generating current peaks and oscillations that can cause instability.

This work proposed a non-isolated DC-DC conversion for high-voltage step-up for PV system applications and current injection in DC nanogrids. The main advantages lie in low component count and use of the leakage inductance associated with the coupled inductors to provide nearly zero current switching (ZCS), leading to minimized switching losses. The stores energy is then recovered, thus avoiding high voltage spikes on the switch and increasing the converter efficiency.

\section{CONVERTER ANALYSIS}

\section{A. Circuit Description}

The proposed converter is shown in Figure 1. The coupled inductances $\mathbb{L}_{P}$ e $L_{S}$ are replaced by the simplified model of a transformer in Figure 3.a, which allows analyzing the influence of the leakage inductances. The number of turns of the primary and secondary windings in the ideal transformer are given by $N_{1}$ and $N_{2}$, respectively. The magnetizing inductance of the transformer corresponds to $\boldsymbol{L}_{\boldsymbol{m}}$, while the leakage inductances are $\boldsymbol{L}_{\boldsymbol{K} \boldsymbol{P}}$ and $\boldsymbol{L}_{\boldsymbol{K} \boldsymbol{S}}$. The circuit composed of capacitor $C_{3}$ and diode $D_{2}$ clamp the voltage across the main switch $S_{l}$, thus absorbing the energy stored in $L_{K P}$ and allowing the use of switches with lower rated voltages and consequently reduced conduction losses. The switched capacitors $C_{1}$ and $C_{2}$ provide higher voltage gain to the converter and damp the resonance associated with the leakage inductances and the intrinsic capacitances of diodes $D_{l}$ and $D_{2}$. The swichting frequency of $S_{l}$ is $f_{S}$. The output side of the converter have current source characteristic provided by $L_{o}$ in series with the output stage represented by a constant voltage $V_{o}$. The converter operates in continuous conduction mode (CCM) since the current through the magnetizing inductance $L_{M}$ does not become null over the switching period. The main theoretical waveforms are presented in Figure 2, while the operation modes are detailed in Figure 3.

\section{B. Operation Stages}

In order to perform the qualitative analysis, capacitances $C_{1}, C_{2}$, and $C_{3}$ are considered large enough so that their respective voltages are constant with negligible ripple. All semiconductors are considered to be ideal and the converter operates in CCM according to Figure 3.

Mode $1\left(\boldsymbol{t}_{\mathbf{0}}-\boldsymbol{t}_{\mathbf{1}}\right)$ : Switch $S_{I}$ is turned on under nearly ZCS condition. The current through $D_{l}$ decreases as limited by $L_{K S}$, being the diode reverse biased at $t_{l}$ with zero current. Inductors $L_{m}$ and $L_{K P}$ store the energy supplied by $V_{I N}$. Diodes $D_{2}$ and $D_{3}$ remain reverse biased. Capacitors $C_{1}, C_{2}$, and $C_{3}$ provide energy to $L_{o}$ and $V_{o}$. This mode finishes when the current through $D_{l}$ becomes null.
Mode $2\left(\boldsymbol{t}_{\mathbf{1}}-\boldsymbol{t}_{\mathbf{2}}\right)$ : Diodes $D_{1}$ and $D_{2}$ are reverse biased at $t_{1}$, while both $S_{I}$ and $D_{3}$ are on. Due to the magnetic coupling, the magnetizing inductance is responsible for charging $C_{2}$, whose voltage depends on the turns ratio between $N_{l}$ and $N_{2}$. Inductances $L_{m}, L_{K P}, L_{K S}$, and $L_{o}$ store energy. Capacitors $C_{l}$, $C_{2}$, and $C_{3}$ provide energy to the DC bus of the nanogrid. This mode finishes when $S_{I}$ is turned off.

Mode $3\left(\boldsymbol{t}_{\mathbf{2}}-\boldsymbol{t}_{\mathbf{3}}\right)$ : Switch $S_{1}$ is turned off at $t_{2}$, while the polarity of the voltage across the inductors is inverted. Diode $D_{1}$ is reverse biased. Diode $D_{2}$ is forward biased and the energy stored in $L_{K P}$ is transferred to $C_{3}$, as the voltage across the switch is clamped with reduced voltage spikes. The current through $D_{3}$ decreases according to a rate defined by $L_{K S}$, as the diode is turned off under ZCS condition and this mode finishes.

Mode $4\left(\boldsymbol{t}_{\mathbf{3}}-\boldsymbol{t}_{\mathbf{4}}\right)$ : Both $S_{1}$ and $D_{3}$ are off at $t_{3}$. Diode $D_{1}$ is forward biased as the current through it is limited by $L_{K S}$. Diode $D_{2}$ is still forward biased, thus allowing $C_{3}$ to be completely charged. Besides, the voltage across $C_{I}$ is proportional to the sum of the voltages across the primary and secondary windings. Inductor $L_{o}$ provides energy to the output stage. This mode finishes when $D_{2}$ is reverse biased.

Mode $5\left(\boldsymbol{t}_{\boldsymbol{4}}-\boldsymbol{t}_{\mathbf{5}}\right)$ : Only diode $D_{1}$ remains forward biased. Capacitor $C_{l}$ is still charged, while $C_{2}, C_{3}$, and $L_{o}$ provide energy to the output stage. This mode finishes when $S_{I}$ is turned on.

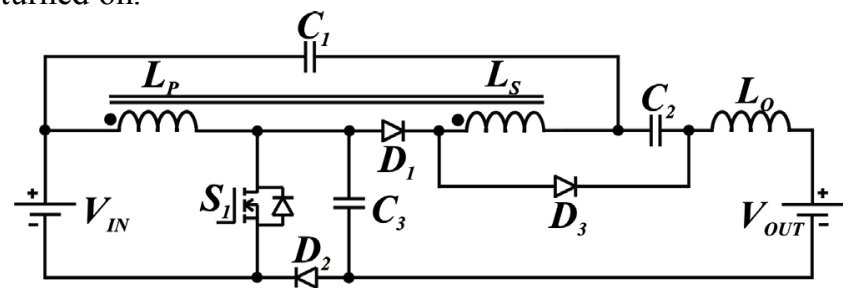

Fig. 1. Proposed coupled inductor based converter.

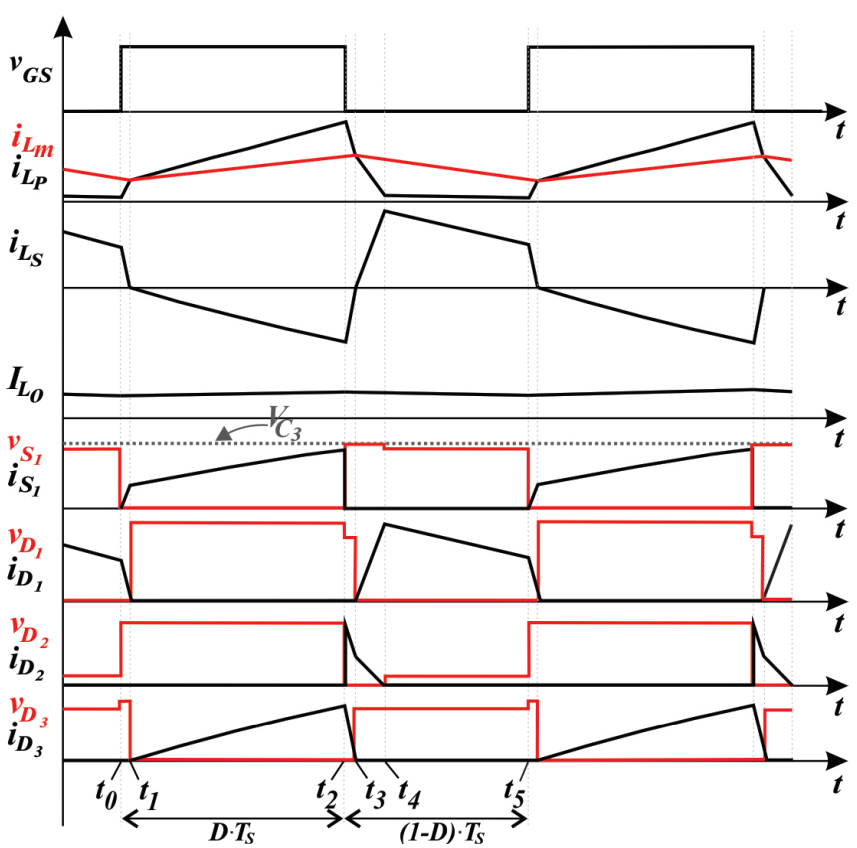

Fig. 2. Main theoretical waveforms of the proposed DC-DC converter. 


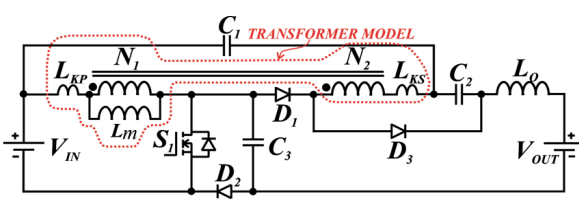

(a)

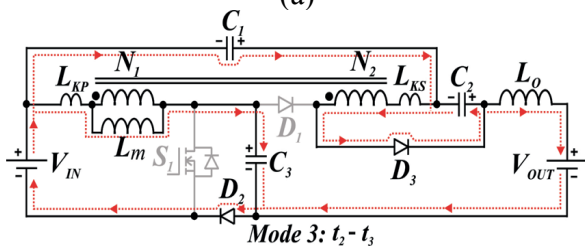

(d)

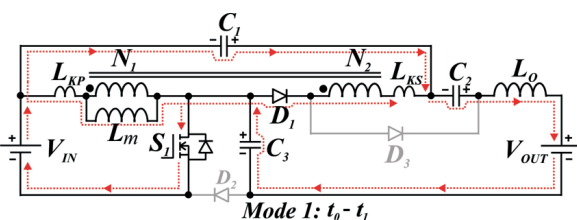

(b)

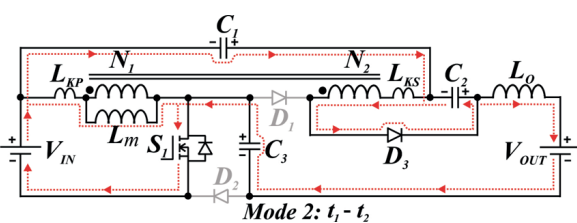

(c)

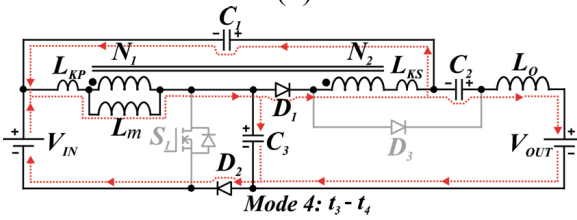

(e)

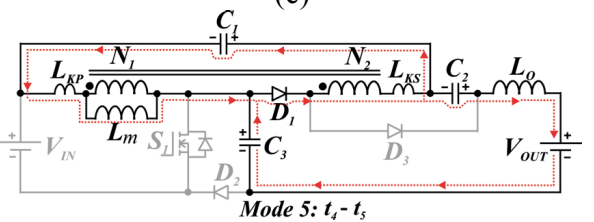

(f)

Fig. 3. (a) Circuit employing an ideal transformer model representing the coupled inductors. Operation modes of the proposed DC-DC converter: (b) Mode 1 $\left(\boldsymbol{t}_{\mathbf{0}}-\boldsymbol{t}_{\mathbf{1}}\right)$; (c) Mode $2\left(\boldsymbol{t}_{\mathbf{1}}-\boldsymbol{t}_{\mathbf{2}}\right)$; (d) Mode $3\left(\boldsymbol{t}_{\mathbf{2}}-\boldsymbol{t}_{\mathbf{3}}\right)$; (e) Mode $4\left(\boldsymbol{t}_{\mathbf{3}}-\boldsymbol{t}_{\mathbf{4}}\right)$; (f) Mode $5\left(\boldsymbol{t}_{\mathbf{4}}-\boldsymbol{t}_{\mathbf{5}}\right)$.

\section{Static Gain}

In order to determine the static gain, switch $S_{l}$ is assumed to be on during $D \cdot T_{s}$ and off during $(1-D) \cdot T_{s}$, where $D$ is the duty cycle and $T_{s}$ is the switching period. The turns ratio of the coupled inductors given by $\boldsymbol{n}$ is:

$$
n=\frac{N_{1}}{N_{2}}
$$

where:

$N_{l}$ - number of turns of the primary winding;

$\mathrm{N}_{2}$ - number of turns of the secondary winding.

Some authors only consider the influence of the primary leakage inductance $L_{K P}$, while neglecting the secondary leakage inductance $L_{K S}$ [26], [40], [41]. It is worth mentioning that $L_{K S}$ is responsible for limiting the $d i / d t$ of the current through the active switch, being an important parameter for the circuit analysis. However, in order to simplify the calculatings, the secondary leakage inductance $L_{K S}$ influence on static gain can be disconsidering. The coupling fator $k$ can be defined [9]:

$$
k=\frac{L_{m}}{L_{m}+L_{K P}+L_{K S} / n^{2}} .
$$

During the time interval defined by $D \cdot T_{s}$, the voltage across the magnetizing inductance is:

$$
V_{L_{m I}}=\frac{L_{t u}}{L_{m}+L_{K P}} \cdot V_{I N}=K \cdot V_{I N}
$$

where $V_{I N}$ is the average input voltage.

The current through the secondary winding is much lower than that through the primary winding. Thus, the influence of $L_{K S}$ on the charging process of capacitors $C_{1}$ and $C_{2}$ can be neglected. Then, the voltage across $C_{2}$ is:

$$
V_{C_{2}}=k \cdot n \cdot V_{I N} \text {. }
$$

During the time interval defined by $(1-D) \cdot T_{s}$, the voltage across the magnetizing inductance is:

$$
V_{L_{m}}=K \cdot\left(V_{C_{3}}-V_{I N}\right) \text {. }
$$

Besides, the voltage across secondary winding $L_{s}$ is equivalent to the reflected voltage $V_{L m}$, i.e.:

$$
V_{L_{S}}=k \cdot n \cdot\left(V_{C_{3}}-V_{I N}\right) \text {. }
$$

The average voltage across $L_{m}$ is null during $T_{s}$, resulting in:

$$
\int_{0}^{T} V_{L_{m I}}(t) d t=\int_{0}^{D T} V_{L_{m}}(t) d t+\int_{\nu T}^{T} V_{L_{m}}(t) d t=0 .
$$

Substituting (3) and (5) in (7) it is possible to determine the average voltage across $C_{3}$ as:

$$
V_{C_{3}}=\frac{1}{1-D} \cdot k \cdot V_{I N}
$$

When switch $S_{l}$ is ed off, capacitor $C_{l}$ is charged with the sum of the voltages across the primary and secondary windings, i.e.:

$$
V_{C_{1}}=k \cdot\left(V_{C_{3}}-V_{I N}\right)+\left(k \cdot n \cdot\left(V_{C_{3}}-V_{I N}\right)\right) .
$$

Substituting (8) in (9), it is possible to determine $V_{C^{\prime}} V_{C_{1}}$ :

$$
V_{C_{1}}=\frac{V_{I N} \cdot D}{1-D} \cdot(1+n) \cdot k
$$

The average output voltage $V_{\text {OUT }}$ corresponds to the sum of the voltages across $C_{1}, C_{2}$, and $C_{3}$ :

$$
V_{\text {OUT }}=\left(\frac{V_{I N} \cdot D \cdot(1+n) \cdot k}{1-D}+V_{I N} \cdot n \cdot k+\frac{k \cdot V_{I N}}{1-D}\right) \text {. }
$$
form:

Rearranging (11), the static gain $M$ can be obtained in the

$$
M=\frac{V_{\text {OUT }}}{V_{I N}}=\frac{1+(D+n) \cdot k}{1-D} .
$$

Considering the ideal model in Figure 1.a, the static gain can be determined for $k=1$ as:

$$
M=\frac{V_{\text {OUT }}}{V_{I N}}=\frac{1+D+n}{1-D} .
$$

The voltage clamping on $S_{1}$ is provided by $C_{3}$. Thus, for $\mathrm{k}=1$ the voltage across $S_{l}$ can be determined substituting (13) in (8):

$$
V_{S_{1}}=V_{c_{3}}=\frac{V_{I N}}{1-D}=\frac{V_{\text {OUT }}}{1+D+n} .
$$

Figure 4.a presents a gain curve of the boost converter and the gain static curves of proposed converter for different coupling factor values.

The equations (15), (16), (17) and (18) calculate the minimum value of the capacitors and the output inductor of 
the converter. The converter switches were chosen according to the voltage and current efforts.

$$
\begin{gathered}
C_{1}^{\prime}=\frac{I_{O} \cdot(1-D)}{f_{s} \cdot \Delta V_{C} \cdot V_{I N} \cdot D \cdot(1+n)} \\
C_{2}=\frac{I_{O}}{f_{s} \cdot \Delta V_{C} \cdot n \cdot V_{I N}} \\
C_{3}=\frac{I_{O} \cdot(1-D)}{f_{s} \cdot \Delta V_{C} \cdot V_{I N}} \\
L_{O}=\frac{V_{I N} \cdot D^{2}}{(1-D) f_{s} \cdot \Delta I_{L o}}
\end{gathered}
$$

where:

$\boldsymbol{\Delta} \boldsymbol{V}_{\boldsymbol{C}}$ - Maximum percentage voltage ripple in the capacitors; $\boldsymbol{\Delta} \boldsymbol{L}_{\boldsymbol{O}}$ - Maximum percentage current ripple in the inductor $L_{O}$.

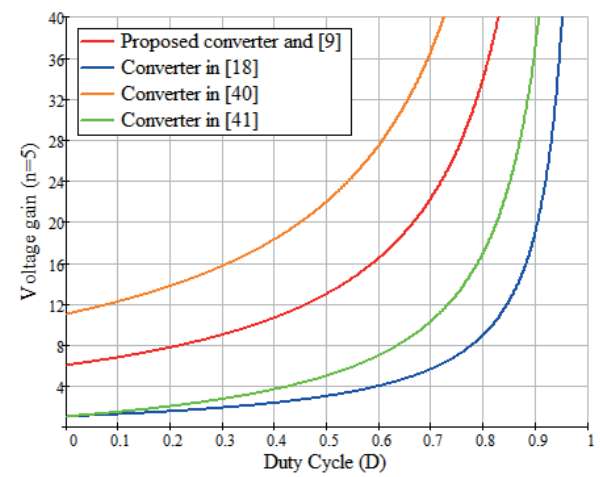

Fig. 4. Ideal static gain curves of the proposed converter and of the

\begin{tabular}{|c|c|}
\hline Parameter & Specifications \\
\hline$S_{1}$ & IRFB4310 (International Rectifier) \\
\hline$D_{1}=D_{3}$ & IDT02S60C (Infineon) \\
\hline$D_{2}$ & STPS3150 (STMicroelectronics) \\
\hline$C_{1}=C_{2}$ & $2 \mu \mathrm{F} / 400 \mathrm{~V}$ (MKP-379 Vishay) \\
\hline$C_{3}$ & $\begin{array}{c}4 \mathrm{x}(10 \mu \mathrm{F} / 100 \mathrm{~V}) \text { Multilayer Ceramic }- \text { MLCC }- \\
\mathrm{SMD} / \mathrm{X} 7 \mathrm{R} / 12105 \mathrm{C} 106 \mathrm{KAT} 2 \mathrm{~A} \text { AVX/Kyocera }\end{array}$ \\
\hline$L_{O}$ & 5 mH -NEE - MTT140EE3007 Magmattec \\
\hline$L_{P} / L_{S}$ & $\begin{array}{c}\text { Core: MTT140EE4012 Magmattec } \\
N_{l}: N_{2}=\mathbf{1 1}: \mathbf{5 5} / L_{p}=\mathbf{5 2} \boldsymbol{\mu H} / L_{s}=\mathbf{1 . 4} \mathbf{~} \boldsymbol{H} \\
L_{K P}=\mathbf{6 5 7} \boldsymbol{n H} / k=0.987\end{array}$ \\
\hline
\end{tabular}
converters presented in table II.

TABLE I

Prototype Components Specifications
D. Comparison Among the Proposed Converter and Other Similar DC-DC Topologies

Table II presents a comparison of the proposed converter with the topologies presented in [9], [18], [40], [41]. Some criteria were considered to select the converters in table II: drive complexity, number of components, photovoltaic applications, high voltage gain and high efficiency. The converter introduced in [9] has current source characteristic at the output. However, it uses an extra diode and capacitor, what may lead to reduced efficiency. The converter proposed in [18] employs few components, but three active switches are necessary, with consequent increase of complexity associated with the drive circuitry. Besides, the output presents voltage source characteristic. A DC-DC interface converter for DC microgrids is described in [40], whose output behaves as a voltage source. Besides, an auxiliary clamping circuit is requited to limit the maximum voltage across the switch, while complexity is increased as a consequence. The high-voltage gain DC-DC converter proposed in [41] presents high efficiency, but the output has voltage source characteristic. Two active switches are also employed in the power stage, resulting in increased cost and reduced robustness. The converter proposed in this manuscript has few components, only one switch which reduces the complexity of activation and output with a current source characteristic which helps in reducing problems associated with the beat frequency [39].

The photovoltaic modules have parasitic capacitances distributed throughout the panel, intrinsic to the manufacture. In the presence of voltage at the terminals of the panel, the load stored by these capacitances can flow through the common point of the system, generating a leakage current that will circulate between the panel and the network. Without galvanic isolation or a common mode filter, the leakage current can be large enough to activate the inverter protection system, removing it from the grid, for example [43], [44]. These currents can cause electromagnetic interference, harmonics in the electrical network and losses in the circuit. In this converter, the $L_{O}$ output inductor can be bypassed to form a common mode filter without changing the converter's operating modes. However, to simplify the operation analysis of the converter, the prototype was developed disregarding the

\begin{tabular}{|c|c|c|c|c|c|}
\hline \multirow[t]{2}{*}{ Parameter } & \multicolumn{5}{|c|}{ Topologies } \\
\hline & Converter in [9] & Converter in [18] & Converter in [40] & Converter in [41] & Proposed converter \\
\hline Diodes & 4 & 2 & 4 & 2 & 3 \\
\hline Switch & 1 & 3 & 2 & 2 & 1 \\
\hline Capacitor & 4 & 1 & 5 & 3 & 3 \\
\hline Coupled Inductor & 1 & 0 & 1 & 0 & 1 \\
\hline Inductor & 1 & 2 & 0 & 3 & 1 \\
\hline Voltage Gain & $1-D$ & $\overline{1-D 1-D 2}$ & $\overline{1-D}$ & $1-D$ & $1-D$ \\
\hline \multirow{2}{*}{$\begin{array}{l}\text { Voltage stress } \\
\text { of main switch }\end{array}$} & $V_{O U T}$ & $V_{O U T}+V_{I N}$ & $V_{\text {OUT }}$ & $V_{\text {OUT }}$ & $V_{O U T}$ \\
\hline & $\overline{1+D+n}$ & 2 & $\overline{1+2 n}$ & $\overline{1+3 D}$ & $\overline{1+D+n}$ \\
\hline Output characteristic & current source & voltage source & voltage source & voltage source & current source \\
\hline $\begin{array}{c}\begin{array}{c}\text { Total number of } \\
\text { components }\end{array} \\
\end{array}$ & 11 & 8 & 12 & 10 & 9 \\
\hline
\end{tabular}
common mode configuration of the inductor.

TABLE II

Comparison Among the Converters Presented in [9], [18], [40], and [41] and the Proposed Topology 


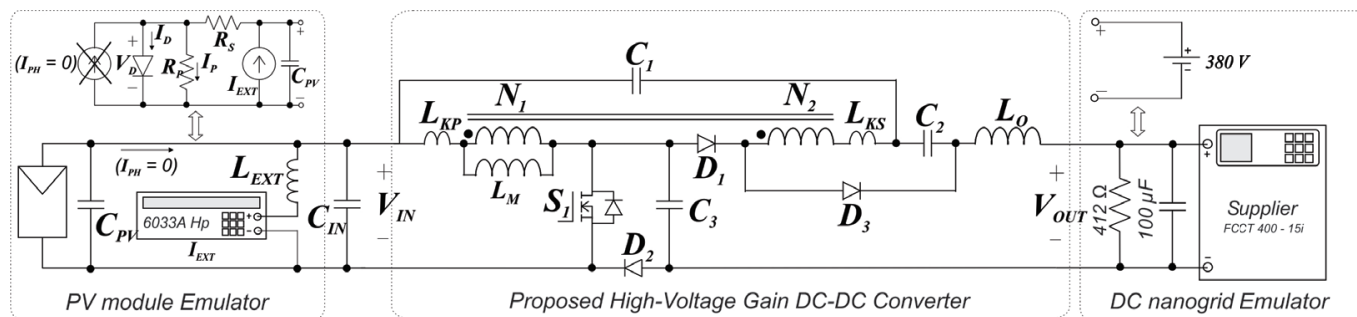

Fig. 5. Laboratory setup using the method proposed in [42], where an external current source is connected to the input to emulated the photogenerated currente. A voltage source is used at the output to emulate DC bus of the nanogrid.

\section{EXPERIMENTAL VALIDANTION}

In order to validate the theoretical assumptions and evaluate the performance of the proposed converter, a $200-\mathrm{W}$ prototype was implemented in the laboratory, being connected to PV module KD210GX-LPU by Kyocera under the manufacturer's standard test conditions. Table I summarizes the components used in the prototype, while Figure 5 presents the experimental setup employed in the tests. The method proposed in [42] was adopted to evaluate the converter in the laboratory, where a PV module emulator is required.

The detailed setup is represented in Figure 5. A programmable source model 6033A by HP is configured to operate as a current source. A voltage source model FCCT400 - $15 \mathrm{i}$ by Supplier was adjusted to provide a DC voltage of 380 $\mathrm{V}$ aiming to emulate the DC nanogrid. This power supply not absorb power. Thus, a $412 \Omega$ interface resistor is added to the output terminals to guarantee the power flux direction of converter to load. The converter was designed with an input voltage of $26 \mathrm{~V}$ while operating at $50 \mathrm{kHz}$. The output voltage and output current are shown Figure 6.a. The voltages across $C_{1}, C_{2}$, and $C_{3}$, and the voltage clamping as provided by $C_{3}$ can be seen in Figures 6.b and 6.c, respectively. Figure 6.d shows the voltage and current waveforms in the active switch, while the detailed view in Figure 6.e denotes low switching losses during turn on. As expected, the maximum voltage across $S_{l}$ is about $60 \mathrm{~V}$. The currents through the primary inductance $\left(I_{L p}\right)$, secondary inductance $\left(I_{L s}\right)$, and magnetizing inductance $\left(I_{L m}\right)$ are represented in Figure 6.f. The commutation of diodes $D_{1}, D_{2}$, and $D_{3}$ is shown in Figures 6.g, $6 . \mathrm{i}$, and $6 . \mathrm{k}$, respectively. The detailed views presented in Figures 6.h, 6.j, and 6.1 clearly evidence that such diodes are turned off under ZCS condition, thus contributing to the minimization of switching losses. The efficiency curve of the converter as a function of the output power for $V_{I N}=26 \mathrm{~V}$ is presented in Figure 7, being measured with power analyzer PA4000 by Tektronix. Since the converter designed for PV applications, EURO (European Efficiency) and the CEC (California Energy Commission) standards were adopted [8], [9], resulting in:

$$
\begin{aligned}
& \eta_{\text {EURO }}=(0.03 \cdot 95.4)+(0.06 \cdot 96.08)+(0.13 \cdot 96.57)+(0.1 \\
& 96.65)+(0.48 \cdot 96.8)+(0.2 \cdot 95.4)=96.38 \% \\
& \eta_{C E C}=(0.04 \cdot 96.08)+(0.05 \cdot 96.57)+(0.12 \cdot 96.65)+(0.21 \\
& \cdot 96.8)+(0.53 \cdot 96.3)+(0.05 \cdot 95.4)=96,4 \% .
\end{aligned}
$$

Analogously to the proposed converter, the topology in [9] has output current source characteristic and presents a maximum efficiency of $94.7 \%$. Considering standards EURO and CEC, the efficiencies become $96.38 \%$ and $96.4 \%$, respectively. Figure 8 shows the distribution of losses among the power stage components, being $D_{2}$ the major responsible for the existing losses due high current conduction. A picture of the laboratory prototype is represented in Figure 9, where capacitor $C_{3}$ is assembled at the bottom layer of the printed circuit board (PCB).

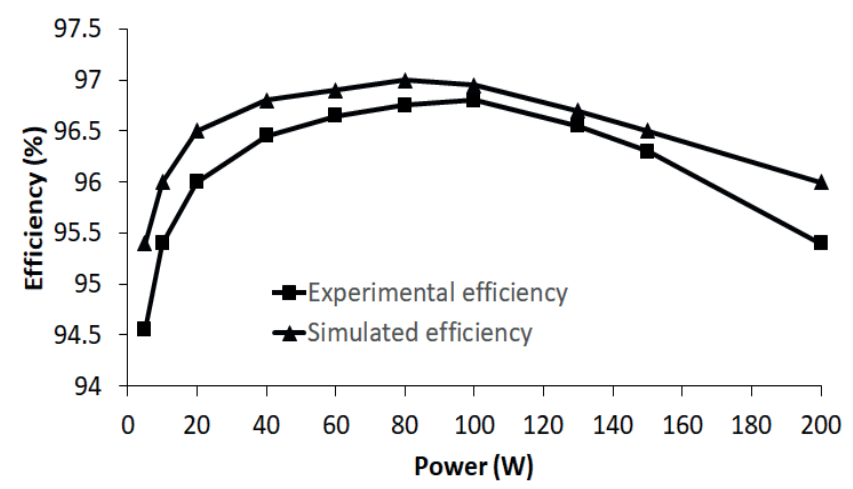

Fig. 7. Efficiency curve of proposed converter for $V_{i N}=26 \mathrm{~V}$.

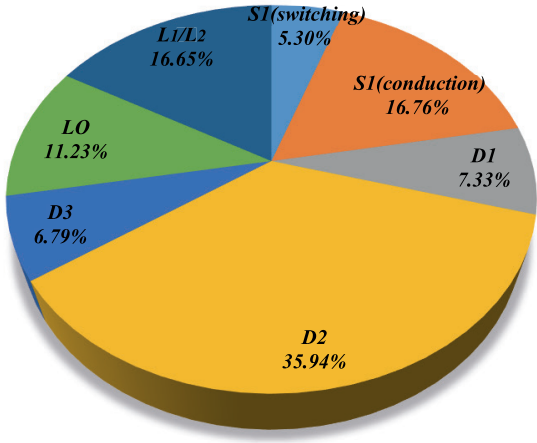

Fig. 8. Percent distribution of losses in the power stage components at the rated power condition.

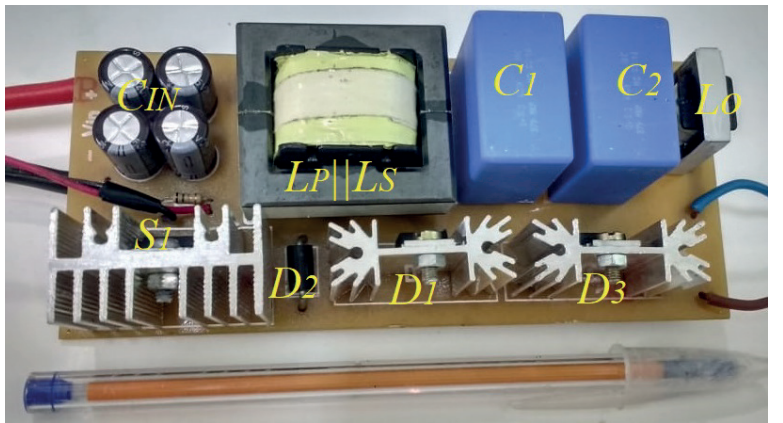

Fig. 9. Laboratory prototype. 

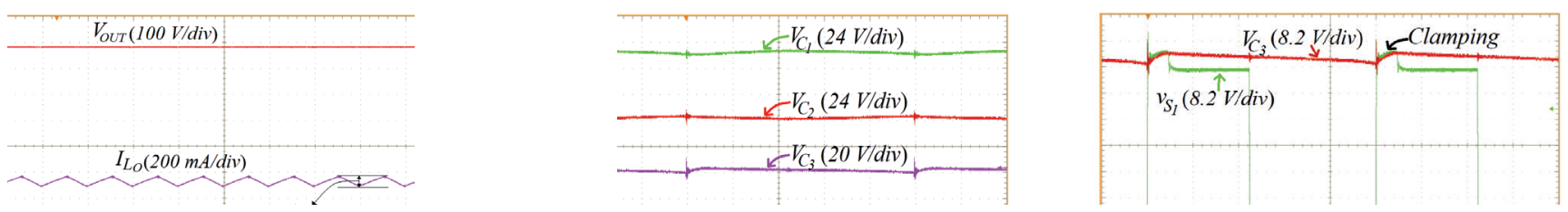

(c)
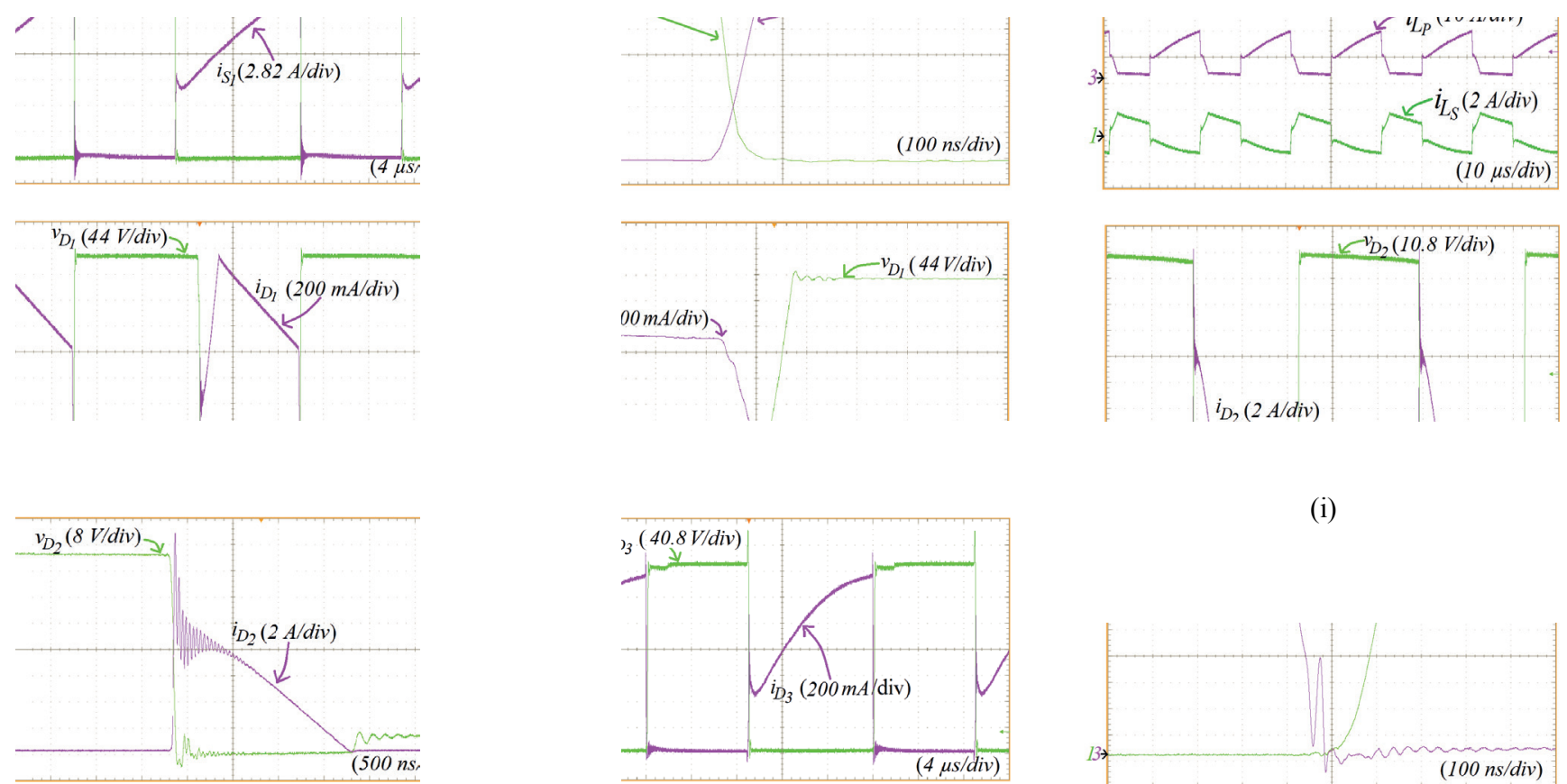

(i)
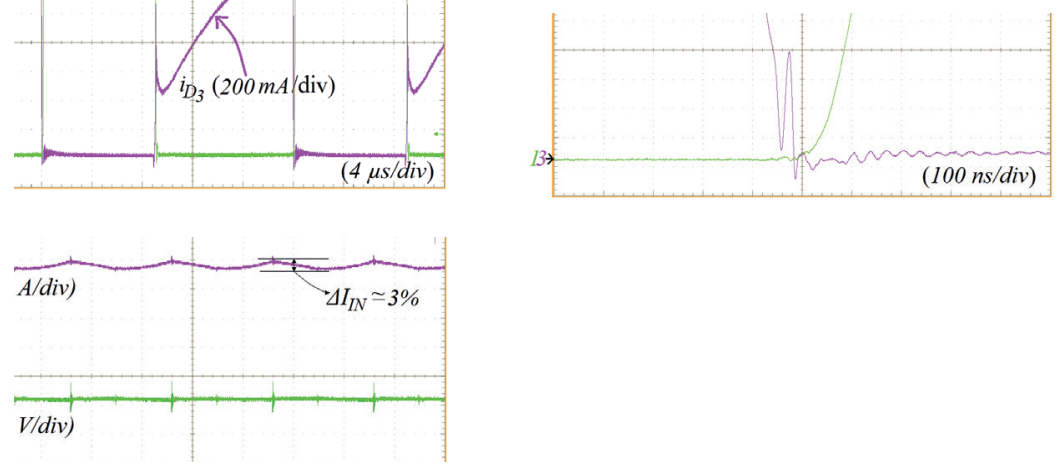

10grids. The qualitative and quantitative analyses of the

, what also contributes to reduction of cost and 
A. Sannino, G. Postiglione, M. H. J. Bollen, and S.

2007.

Sustain. Energ ， vol. 67,

DC converter UK with current source characteristic for

S. Ahmadi, H. ani, S. Shokoohi, and E. Hasanii, “An

"Performance enhancement of hybrid AC/DC microgrid
S. S. Nag, R. Adda, O. Ray, and S. K. Mishra, "Current

(ICIC) $\quad 54$, no. 1, pp. $13 \quad 1355$

IEEE Annu. Power Electron. Spec. Conf. vol. 3, pp.

systems," 汭 Energy Convers. Congr. Expo. ECCE

Brazilian Power Electron. Conf. COBEP $2 \mathrm{C}$

Proc. based grid application,” l. Energy 90, pp. 64 
Trans. Power Electron., vol. 32, no. 1, pp. 353-362, jan 2017.

[29] Y. P. Siwakoti, F. Blaabjerg, and P. C. Loh, "Ultra-stepup DC-DC converter with integrated autotransformer and coupled inductor," Conf. Proc. - IEEE Appl. Power Electron. Conf. Expo. - APEC, vol. 2016-May, no. 1, pp. 1872-1877, may 2016.

[30] Y. P. Siwakoti and F. Blaabjerg, "Single Switch Nonisolated Ultra-Step-Up DC-DC Converter with an Integrated Coupled Inductor for High Boost Applications," IEEE Trans. Power Electron., vol. 32, no. 11, pp. 8544-8558, nov 2017.

[31] A. M. S. S. Andrade, L. Schuch, and M. L. Da Silva Martins, "Analysis and design of high-efficiency hybrid high step-Up DC-DC converter for distributed PV generation systems," IEEE Trans. Ind. Electron., vol. 66, no. 5, pp. 3860-3868, may 2019.

[32] Y. Wang, Y. Qiu, Q. Bian, Y. Guan, and D. Xu, “A Single Switch Quadratic Boost High Step Up DC-DC Converter," IEEE Trans. Ind. Electron., vol. 66, no. 6, pp. 4387-4397, april 2019.

[33] M. Forouzesh, Y. P. Siwakoti, S. A. Gorji, F. Blaabjerg, and B. Lehman, "Step-Up DC-DC converters: A comprehensive review of voltage-boosting techniques, topologies, and applications," IEEE Trans. Power Electron., vol. 32, no. 12, pp. 9143-9178, dec 2017.

[34] E. S. Hass, C. B. Nascimento, E. S. Hass, and C. B. Nascimento, "A SIMPLE SELF-CLAMPED HIGH STEP-UP DC-DC CONVERTER EMPLOYING COUPLED INDUCTOR A Simple Self-Clamped High Step-Up DC-Dc Converter Employing Coupled Inductor," pp. 204-213, june 2019.

[35] L. Schmitz, A. I. Pereira, R. G. A. Cacau, D. C. Martins, and R. F. Coelho, "CONVERSOR CC-CC DE ALTO GANHO BASEADO NO CONVERSOR ĆUK COM INDUTOR ACOPLADO E MULTIPLICADORES DE TENSÃO," pp. 267-276, sept 2019.

[36] Qun Zhao, Fengfeng Tao, Yongxuan Hu, and F. C. Lee, "Active-clamp DC/DC converters using magnetic switches," APEC 2001. Sixt. Annu. IEEE Appl. Power Electron. Conf. Expo. (Cat. No.01CH37181), vol. 2, pp. 946-952, aug 2001.

[37] Q. Zhao and F. C. Lee, "High-efficiency, high step-up dc-dc converters," IEEE Trans. Power Electron., vol. 18, no. 1 I, pp. 65-73, jan 2003.

[38] D. M. Van De Sype, K. De Gussem, B. Renders, A. P. Van Den Bossche, and J. A. Melkebeek, "A single switch boost converter with a high conversion ratio," Conf. Proc. - IEEE Appl. Power Electron. Conf. Expo. - APEC, vol. 3, pp. 1581-1587, june 2005.

[39] X. Yue, D. Boroyevich, F. C. Lee, F. Chen, R. Burgos, and F. Zhuo, "Beat Frequency Oscillation Analysis for Power Electronic Converters in DC Nanogrid Based on Crossed Frequency Output Impedance Matrix Model," IEEE Trans. Power Electron., vol. 33, no. 4, pp. 30523064, april 2018.
[40] S. Sathyan, H. M. Suryawanshi, B. Singh, C. Chakraborty, V. Verma, and M. S. Ballal, "ZVS-ZCS High Voltage Gain Integrated Boost Converter for DC Microgrid," IEEE Trans. Ind. Electron., vol. 63, no. 11, pp. 6898-6908, nov 2016.

[41] M. Forouzesh, Y. Shen, K. Yari, Y. P. Siwakoti, and F. Blaabjerg, "High-Efficiency High Step-Up DC-DC Converter with Dual Coupled Inductors for GridConnected Photovoltaic Systems," IEEE Trans. Power Electron., vol. 33, no. 7, pp. 5967-5982, july 2018.

[42] S. Qin, K. A. Kim, and R. C. N. Pilawa-Podgurski, "Laboratory emulation of a photovoltaic module for controllable insolation and realistic dynamic performance," IEEE Power Energy Conf. Illinois, PECI 2013, pp. 23-29, april 2013.

[43] F. Chen, R. Burgos, and D. Boroyevich, "A Transformerless Single-Phase Utility Interface Converter to Attenuate Common-Mode Voltage for DC Microgrid," pp. 157-162, july 2017.

[44] V. D. S. Member, V. John, and S. Member, "A Modified Common-Mode Filter with Enhanced Attenuation Performance in Single-Phase Grid-Tied Solar PV Inverters," pp. 5-10, april 2020.

\section{BIOGRAPHIES}

Yury Pontes, born in 07/05/1992 in Fortaleza-CE, is an electrical engineer (2016) from Federal University of Ceará and master (2019) from Federal University of Ceará. He is currently a professor at National Industrial Training Service (SENAI). His areas of interest are: power electronics, electronic control systems and renewable energy.

Carlos Elmano de A. e Silva, Graduated (2004), master's (2007) and doctorate (2012) in Electrical Engineering from the Federal University of Ceará. He is currently professor of undergraduate and master's courses in electrical engineering and computer engineering at UFC - Sobral. Has experience in the area of Electrical Engineering, with an emphasis on power electronics, acting mainly on the following themes: threephase rectifiers, power factor correction and wind energy conversion systems.

Edilson Mineiro Sá Jr., graduated in engineering electrical Engineering at the Federal University of Ceará (1999), Master in Electrical Engineering from Federal University of Ceará (2004) and doctorate from the Federal University of Santa Catarina (2010). He is currently an effective professor of Federal Institute of Education, Science and Technology Campus Sobral and regular professor of the Postgraduate Program in Electrical and Computer Engineering at Federal University of Ceará, Sobral. His areas of interest are: electronic ballasts, microcontrollers, LEDs for illumination, circuits for factor correction power and photovoltaic systems. $\mathrm{He}$ is a member of the Association Brazilian Power Electronics - SOBRAEP. 